\title{
Who is behind the stocking of energy-dense foods and beverages in small stores? The importance of food and beverage distributors
}

\author{
Guadalupe X Ayala ${ }^{1,2, *}$, Heather D'Angelo ${ }^{3}$, Joel Gittelsohn ${ }^{4}$, Lucy Horton ${ }^{2}$, Kurt Ribis ${ }^{3}$, \\ Lesley Schmidt Sindberg ${ }^{5}$, Christina Olson ${ }^{1,6}$, Anna Kharmats ${ }^{7}$ and Melissa N Laska ${ }^{5}$ \\ ${ }^{1}$ College of Health and Human Services, San Diego State University, San Diego, CA, USA: ${ }^{2}$ Institute for Behavioral \\ and Community Health, 9245 Sky Park Court, Suite 220, San Diego, CA 92123, USA: ${ }^{3}$ Department of Health \\ Behavior, Gillings School of Global Public Health, University of North Carolina at Chapel Hill, Chapel Hill, NC, USA: \\ ${ }^{4}$ Bloomberg School of Public Health, John Hopkins Global Center on Childhood Obesity, Johns Hopkins University, \\ Baltimore, MD, USA: ${ }^{5}$ Division of Epidemiology and Community Health, School of Public Health, University of \\ Minnesota, Minneapolis, MN, USA: 'Division of Health Promotion, Graduate School of Public Health, San Diego \\ State University, San Diego, CA, USA: ${ }^{7}$ Bloomberg School of Public Health, Johns Hopkins University, Baltimore, \\ MD, USA
}

Submitted 29 August 2015: Final revision received 22 November 2016: Accepted 14 December 2016: First published online 3 October 2017

\begin{abstract}
Objective: The present study examined food and beverage distributors' sourcing, placement and promotion of obesogenic (energy-dense, nutrient-poor) product categories from the perspective of small food store owners/managers. The obesogenic product categories of interest were savoury snacks, sugary beverages, sweet snacks, confectionery and frozen treats. Specifically, we examined how frequently distributors sourced these products, and the types of agreements and expectations they had for their placement and promotion. Differences were explored by store size and ethnicity. Fresh produce was used as a comparison when examining differences in frequency of sourcing only, with implications for healthy food access.

Design: Survey research involving in-person interviews.

Setting: Four urban areas in the USA: Baltimore, MD; Durham, NC; Minneapolis/ St. Paul, MN; and San Diego, CA.

Subjects: Seventy-two small food store owners/managers, 65\% consent rate.

Results: Most distributors sourced obesogenic products weekly. Agreements to place products were predominantly informal (e.g. handshake) with sweet snack, confectionery and frozen treat distributors, and formal (e.g. contract) with savoury snack and sugary beverage distributors. Free-standing displays were the most common incentive provided by distributors and they expected some control over their placement and pricing. Free/discounted products and signage were also common incentives but slotting fees were not. Smaller stores and ethnic stores were less likely to receive various incentives, but among sweet snack distributors, they were more likely to control the price in ethnic $v$. non-ethnic stores.

Conclusions: Obesogenic products are ubiquitous. Influencing what is made available to consumers in the retail food environment needs to consider the distributor.
\end{abstract}

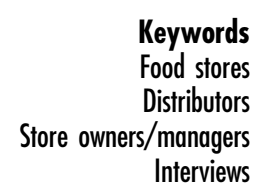

Food stores Distributors Interviews
Evidence from national and international studies demonstrates that energy-dense, nutrient-poor foods and beverages (i.e. obesogenic products) are readily available in many retail food environments ${ }^{(1)}$, including small food stores $^{(2)}$, while healthy consumable products are not ${ }^{(3)}$. Obesogenic products are also accessible (i.e. ready-toconsume), thus they contribute to excess energy intake and risk for obesity ${ }^{(4)}$. Among children of primary school age, adolescents and adults aged 20-50 years, foods and beverages purchased from food stores accounted for $63 \%$ of individual dietary energy across all age groups ${ }^{(5)}$. Among the top foods and beverages contributing to energy purchased were grain-based desserts and sodas, among others ${ }^{(5)}$, foods and beverages that have been identified as dietary risks for obesity ${ }^{(6-8)}$. Small food stores (also known as limited assortment food stores, convenience/corner stores and ethnic stores) are all variations on a theme, being stores that are conveniently located 
(walkable, in close proximity) to one's home, school and/ or workplace and with sufficient product varieties to complete a fill-in or quick, single meal shopping trip ${ }^{(9)}$. Small food stores have become an increasingly important retail food environment, with market share increasing from $27 \%$ in 2015 to $38 \%$ in $2016^{(9)}$. However, unlike supermarkets and supercentres, they carry fewer healthy products, such as little to no fresh fruits and vegetables ${ }^{(3)}$. Given that small food stores are ubiquitous in low- $v$. highincome communities ${ }^{(10)}$, they are important intervention targets to address obesity-related health disparities ${ }^{(11)}$.

Although findings are mixed ${ }^{(12,13)}$, research suggests that small food store interventions are feasible to implement and effective at improving customers' dietary knowledge, attitudes and behaviours ${ }^{(14,15)}$. Several interventions have resulted in increases in fruit and vegetable purchasing and consumption ${ }^{(16,17)}$. Other research supports labelling and other marketing strategies to decrease the purchase of obesogenic products, including sugary beverages $^{(18,19)}$. Despite these early successes, challenges remain in understanding how best to partner with small food stores to modify the placement and promotion of highly palatable and profitable obesogenic products ${ }^{(20)}$.

Led primarily by marketing, consumer affairs and food retail researchers, there is a body of research on the importance of food and beverage distributors and manufacturers in the sourcing, placement and promotion of products in food stores. However, with a few exceptions in tobacco ${ }^{(21-23)}$ and more recently food and beverage products $^{(24,25)}$, public health research on the role of distributors/manufacturers in the sourcing, placement and promotion of obesogenic products is almost non-existent. Among the dominant themes of distributor/manufacturer research in food stores is the use of slotting fees and other incentives to place and promote products ${ }^{(26,27)}$. Delivery of products to the store and display maintenance have been identified as important assets in these relationships ${ }^{(28)}$. Public health researchers, in turn, have examined the contracts that store owners have with distributors/ manufacturers, comparing soft drink, candy and snack distributors/manufacturers. They found that soft drink distributors/manufacturers were more likely to give trade allowances (i.e. free goods or price reductions) compared with candy and snack distributors/manufacturers ${ }^{(29)}$. Notwithstanding this evidence, distributors are understudied in food systems research, particularly as it relates to the potential promotion of healthy foods and beverages whether by making them more available or moving the unhealthy products to less prominent locations in the store $^{(30)}$. Hattersley proposed a model that considers the importance of distributors in the sourcing and placement of fresh fruits and vegetables ${ }^{(31)}$. However, an intervention seeking to improve access to healthy foods by working with distributors found low-to-moderate fidelity in their involvement in stocking healthy products ${ }^{(32)}$. Thus, more research is needed on the importance of food and beverage distributors in the placement and promotion of products. This is urgently needed with small food stores given that they are an important retail food environment for the distribution and sale of foods and beverages in the $\mathrm{USA}^{(33,34)}$ and they are understudied in retail food environment research.

In the present study, interviews were conducted with small food store owners/managers to understand how food and beverage distributors are involved in the sourcing, placement and promotion of five obesogenic product categories: savoury snacks (i.e. chips and other salty snacks), sugary beverages (i.e. soft drinks, sports and energy drinks), sweet snacks (i.e. snack cakes and cookies), confectionery (i.e. candies and chocolate) and frozen treats (i.e. ice cream and frozen sweet desserts). Distributors refer to those individuals who source products to a store; in many cases, they are also involved in the products' placement and promotion within the store. Distributors were examined from the store owner/manager's perspective in two ways: (i) how frequently do distributors source their products to the stores; and (ii) what types of agreements and expectations do distributors have for placing and promoting their products in the stores? In addition, fresh fruits and vegetables were examined as a healthy product comparison category in terms of frequency of sourcing only, to better understand potential disparities in healthy food access. Finally, in exploratory analyses, we examined for differences by store size and store ethnicity. The research seeks to identify novel aspects of the food environment with the potential to influence execution of healthy food access initiatives, in order to reduce the significant racial/ethnic and socio-economic disparities in obesity risk $^{(35)}$.

\section{Methods}

\section{Study design}

This cross-sectional study involved a single interview with seventy-two owners/managers of small food stores. Data collection occurred between mid-October 2013 and July 2014 in four major metropolitan cities in the USA: Baltimore, MD; Durham, NC; Minneapolis/St. Paul, MN; and San Diego, CA. Cities were selected based on investigators' experience conducting research with food stores in their communities, thus maximizing the feasibility for obtaining these sensitive data. Analyses and verification were completed from October 2014 to June 2015.

\section{Store recruitment and data collection}

Food stores were identified using two methods: (i) an enumerated list of food stores in the target geographic region based on several sources of data including business and public health databases (Durham and San Diego); and (ii) a list of food stores previously involved in research and other programming efforts (Baltimore and 
Minneapolis/St. Paul). A trained research associate visited each potential store and assessed initial eligibility by completing an observation checklist. Stores were eligible if they were located in a low- to middle-income neighbourhood based on US Census data and if they had three or fewer cash registers. Although important for characterizing the food environment, supermarkets, big box chains, corporate-managed convenience stores and dollar stores were not approached given potential differences in owner/manager decision-making authority ${ }^{(36)}$.

\section{Owner/manager recruitment and data collection}

Stores that met the initial screening criteria underwent a second screening conducted with the owner/manager. Owners/managers were eligible if they negotiated purchase agreements with sales representatives, distributors and wholesalers themselves; if these agreements were negotiated on behalf of the approached store only; if the owner/manager had at least 1 year of experience with the store; and if he/she was at least 18 years of age. The former two criteria helped ensure that the research associate was speaking with the right person and to minimize possible variations introduced by multiple store contracts. The latter two criteria helped ensure that the owner/manager had sufficient experience with store management and could provide informed consent. Owners/managers were excluded if they refused to be audio-recorded.

If eligible, the research associate obtained informed consent and conducted the interview either immediately or at a later date. Spanish-language interview guides were used by trained, bilingual (English/Spanish) research associates to conduct five Spanish-language interviews in San Diego and a bilingual trained research associate conducted eight Korean language interviews using the English guide in Baltimore (see Table 1). Response cards were used to collect demographic information. Interviews lasted between 40 and $140 \mathrm{~min}$, in part because interviews were often conducted on-site requiring the owner/ manager to attend to business while the research associate waited for his/her availability. Following completion of the interview, the owner/manager received cash or a gift card valued at \$US 25.00. Table 1 reports on the number of stores approached, as well as the number determined eligible, ineligible (e.g. too many cash registers) and refused during initial screening.

\section{Interview guide}

The interview guide was developed following several conference calls between investigators and research associates. Owners/managers responded to closed-ended questions on their relationship with these distributors. The term distributor was used to refer to the individual with whom the store owner/manager interacted in the delivery of the products to the store; however, we acknowledge that the agreements may be partly dictated by other individuals, including the manufacturers. Closed-ended questions were adapted from previous work ${ }^{(22,29,37)}$ and revised through an iterative process of group feedback and discussion, drawing particularly from extensive previous fieldwork with small food stores ${ }^{(38-40)}$ and a pilot test in San Diego, CA. The categories of information included in the interview guide were: frequency of sourcing the target products; types of agreements for the sourcing, placement and promotion of target products; incentives received and distributor expectations for those products and incentives, including control over displays and their placement; and store and owner/manager characteristics. To minimize respondent burden, questions about the healthy comparison of fresh fruits and vegetables were limited to sourcing. From among the variables considered, sourcing was identified as the most relevant for understanding challenges and implications for healthy food access. It also allowed us to better understand potential differences in the owner/manager-distributor relationship, at least in terms of frequency of contact, while not unduly burdening the owner/manager with a lot of questions.

\section{Frequency of product sourcing}

Owners/managers were asked if distributors delivered their products directly to the stores and if yes, how often delivery occurred: $1=$ annually, $2=$ every six months, $3=$ quarterly, $4=$ monthly or $5=$ weekly or more often. To reduce respondent burden, the same response options were used for all product categories despite the limited plausibility of some combinations (e.g. annual fresh fruit and vegetable delivery). Responses were collapsed into four categories: weekly, monthly, quarterly to annually, or sourced product themselves (e.g. purchased confectionery products at a big box chain store such as Sam's Club).

For product categories that were sourced by the owner/ manager or a store employee, no additional questions were asked of that product category given the emphasis on owner/manager-distributor contact. Stores not carrying a specific product category were removed from analyses involving this variable.

\section{Types of agreements}

For all product categories sourced by distributors, owners/ managers were asked if they had agreements with distributors for the sourcing, placement and promotion of their products in the store. If yes, a follow-up question asked whether these agreements were informal (e.g. verbal agreement, handshake, etc.), formal (e.g. written contract) or of both types. The latter two were collapsed into the formal type.

\section{Incentives and expectations}

Owners/managers were asked about the types of incentives they received from distributors to place and promote their products in their store, including displays, free or discounted products, signage and other marketing materials, and slotting payments (fees paid to stock products 
usually in a prescribed location in the store). Owners/ managers were also asked about what was expected of the store in exchange for the incentives they received, including price control, location control, employee promoting the product and other. In addition, owners/ managers were asked to quantify how much control distributors had over placement of displays from $0=$ no control (i.e. 'the sales rep is not allowed to do anything without first checking with you') to $4=$ total control (i.e. 'the sales rep decides where and how to display products in your store without your input'). For each of the product categories where at least a little control was reported over displays (responses 1 to 4), this question was followed with a second question asking about the location of the displays in question, including whether they were at the checkout, aisle shelf, end cap (i.e. end-ofaisle displays) or other locations. For sugary beverages and frozen treats, this latter location included coolers.

\section{Store and owner/manager characteristics}

A final set of questions asked about total annual store sales and whether the store was certified to serve as a Special Supplemental Nutrition Program for Women, Infants, and Children (WIC) vendor, qualifying the store to receive federally funded WIC cheques for the purchase of certain products such as fresh fruits and vegetables. Annual sales were collapsed into two categories $(1=\geq \$$ US $500000 v$. $0=<\$$ US 500000) to explore whether relationships differed by store size based on sales. This categorization was based on two factors: distribution of the data (i.e. sufficient numbers to draw meaningful comparisons) and previous research. Regarding the latter, small food stores have been identified as having annual sales of approximately \$US 1 million; a median split at \$US 500000 allows for a more granular analysis by store size. Owner/manager characteristics included age, gender, education and years managed the store. After the interview, the research associate coded the store ethnicity into one of five categories based on the language of store signage, language used by employees and clientele, as well as types of food products: (i) not ethnicity specific, (ii) Latino, (iii) African or African-American, (iv) Asian or (v) a combination of these. Inter-rater reliability for this item was high (98-100\%) given the prominent features representing ethnicity in a store. Store ethnicity was then collapsed into $1=$ ethnic store $v$. $0=$ no specific ethnicity to explore whether relationships differed by store ethnicity.

\section{Statistical analyses}

All data cleaning and analyses were completed using the statistical software package IBM SPSS Statistics Version 22.0. Descriptive statistics, $\chi^{2}$ tests and $t$ tests were used to examine characteristics of the stores and store owners/ managers and distributor variables, overall and by store size and store ethnicity for each product category.

\section{Results}

\section{Recruitment}

Two hundred and twenty-one stores were approached for participation; fifty-five remained undetermined given no contact with the owner/manager despite several attempts and one store was closed. Of the remaining 165 stores, $29 \%$ ( $n$ 48) were ineligible to participate for the following reasons: ten had more than three cash registers; ten had contracts negotiated by a corporate office; eight had owners/managers involved in store management for less than 1 year; six were liquor stores; six presented language barriers; and eight were excluded for other reasons such as having more than one location. Another 25\% ( $n$ 42) refused participation and 2\% ( $n$ 3) of interviews were incomplete. The overall recruitment rate was $65 \%$ and site-specific recruitment rates ranged from $46 \%$ to $83 \%$, with lower rates in the two communities where there were no pre-existing relationships with the owners/managers (46\% Durham, NC; $51 \%$ San Diego, CA; $81 \%$ Baltimore, MD; $83 \%$ Minneapolis, MN; see Table 1).

\section{Owner/manager and store characteristics}

The owners/managers were mostly middle-aged men with more than a high school education and an average of 7 years of experience managing the store (see Table 2). Nearly half of the stores were characterized as ethnic markets ( $44 \% v .56 \%$ of no specific ethnicity) and a similar percentage were authorized to accept WIC. Although the stores were all characterized as small based on number of cash registers, they varied in annual sales, similar to a previous study ${ }^{(3)}$. Dichotomizing annual sales using a median split resulted in two fairly equivalent groups of thirty-eight ( $60 \%$ with sales of < \$US 500000 per annum) smaller stores and twenty-five ( $40 \%$ with sales of $\geq$ \$US 500000 per annum) larger stores. Similar percentages of ethnic and non-ethnic stores were classified into smaller $v$. larger stores $(P>0.05)$; however, more non-ethnic stores were larger compared with ethnic stores.

Given differences in sampling methods and recruitment rates across sites, we examined differences between sites prior to answering our study questions. Site differences in store characteristics were observed on several variables. For example, $73 \%$ of participating San Diego stores were larger stores based on annual sales of $\geq \$$ US 500000 compared with $42 \%$ of Minneapolis stores, $25 \%$ of Durham stores and $15 \%$ of Baltimore stores. Similarly, participating Baltimore stores had fewer aisles (mean $=2)$ compared with stores in Durham (mean $=4)$, Minneapolis/ St. Paul $($ mean $=3)$ and San Diego $($ mean $=3 ; P \leq 0 \cdot 001)$. In addition, half or more of the stores in San Diego (50\%), Durham (56\%) and Baltimore (65\%) were classified as ethnic stores, whereas only $10 \%$ of the Minneapolis/St. Paul stores were ethnic stores $(P \leq 0 \cdot 01)$. These site differences support our examination of differences by store size 
Table 1 Small food store recruitment and language of interview $(n 72)$ in four urban areas in the USA, midOctober 2013 to July 2014

\begin{tabular}{|c|c|c|c|c|c|c|c|c|}
\hline \multirow[b]{2}{*}{ Study site } & \multirow{2}{*}{$\begin{array}{c}\text { Stores } \\
\text { approached }(n)\end{array}$} & \multicolumn{5}{|c|}{ Recruitment outcome $(n)$} & \multirow{2}{*}{$\begin{array}{l}\text { Recruitment } \\
\text { rate }(\%) \dagger\end{array}$} & \multirow{2}{*}{$\begin{array}{l}\text { Completed by language } \\
\text { of interview }(n)\end{array}$} \\
\hline & & $\mathrm{R}$ & NE & $U$ & C & I & & \\
\hline Baltimore, MD & 21 & 2 & 1 & 0 & 0 & 1 & 81 & 9 English, 8 Korean \\
\hline Durham, NC & 77 & 18 & 21 & 21 & 0 & 1 & 46 & 16 English \\
\hline Minneapolis, MN & 32 & 4 & 5 & 4 & 0 & 0 & 83 & 19 English \\
\hline San Diego, CA & 91 & 18 & 21 & 30 & 1 & 1 & 51 & 15 English, 5 Spanish \\
\hline Total $n$ or average $\%$ & 221 & 42 & 48 & 55 & 1 & 3 & 65 & 59 English, 8 Korean, 5 Spanish \\
\hline
\end{tabular}

$\mathrm{R}$, refused; NE, not eligible; $\mathrm{U}$, undetermined; $\mathrm{C}$, closed; I, incomplete.

†Completed/[approached - (not eligible + undetermined + closed)].

Table 2 Demographic characteristics of participating stores and owners/managers $(n 72)$ of four urban areas in the USA (Baltimore, MD; Durham, NC; Minneapolis/St Paul, MN; and San Diego, CA), mid-October 2013 to July 2014

\begin{tabular}{|c|c|c|c|}
\hline & Median or \% & Range or $n$ & Missing $(n)$ \\
\hline \multicolumn{4}{|l|}{ Store owners/managers } \\
\hline Male $(\%$ and $n)$ & 90 & 65 & 0 \\
\hline$>$ High school education ( $\%$ and $n$ ) & 68 & 49 & 0 \\
\hline Years managed store (median and range) & 7 & $1-40$ & 1 \\
\hline Store aisles (median and range) & 3 & $0-8$ & 1 \\
\hline Annual sales $(\%$ and $n$ ) & & & 9 \\
\hline$<\$ U S 250000$ to $<\$$ US 500000 & 60 & 38 & \\
\hline$>\$$ US 500000 to >\$US 1000000 & 40 & 25 & \\
\hline WIC authorized $(\%$ and $n)$ & 43 & 31 & 0 \\
\hline Store ethnicity ( $\%$ and $n)$ & & & 0 \\
\hline Latino/Hispanic \& African/African-American & 10 & 7 & \\
\hline Korean & 5 & 4 & \\
\hline
\end{tabular}

WIC, Special Supplemental Nutrition Program for Women, Infants, and Children.

and store ethnicity, and we acknowledge the limitation of not controlling for site in our analyses given the sample size.

\section{Question 1: How often are products sourced?}

Savoury snacks, sugary beverages and sweet snacks were most often sourced by a distributor at least weekly (in $85 \%, 72 \%$ and $68 \%$ of the stores, respectively; see Fig. 1). There were few differences in sourcing by store size (data not shown). Smaller stores were more likely to self-source sugary beverages $(8 \%)$ or receive monthly distributions (25\%) compared with larger stores (0\% and $4 \%$, respectively; $P \leq 0.05)$. There were no differences by store ethnicity in the sourcing of obesogenic product categories.

In terms of fresh fruits and vegetables, converse to what is reported for the obesogenic product categories, $21 \%$ of the stores did not stock any fresh fruits and vegetables, $53 \%$ self-sourced fruits and vegetables, and 23\% had a fresh fruit and vegetable distributor (3\% missing). Smaller stores were also more likely to self-source fresh fruits and vegetables (70\%) or not stock fresh fruits and vegetables at all (24\%), compared with larger stores ( $45 \%$ and $8 \%$, respectively; $P \leq 0 \cdot 001)$.

\section{Question 2: What types of agreements and expectations do distributors have for carrying products?}

Agreements were in place between owners/managers and distributors for most product categories (see Table 3). Similar percentages of savoury snack (43\%), sugary beverage ( $51 \%$ ), and frozen treat ( $40 \%$ ) distributors had formal agreements (i.e. contracts). Informal agreements dominated among sweet snack (62\%) and confectionery (57\%) distributors, and were least common among sugary beverage distributors (37\%). Differences in types of agreements were not observed by store size or store ethnicity for any of the product categories.

In close to two-thirds of the stores, some type of incentive was received for placing and promoting products, and the most common incentives were displays (83-98\%; see Table 3) such as free-standing wire racks and displays to attach at end caps. The next most common incentive was free or discounted products from savoury snack (40\%), sugary beverage (63\%) and confectionery (80\%) distributors. The provision of free signage and marketing materials was somewhat common among sugary beverage (53\%) and confectionery (46\%) distributors. Least common 


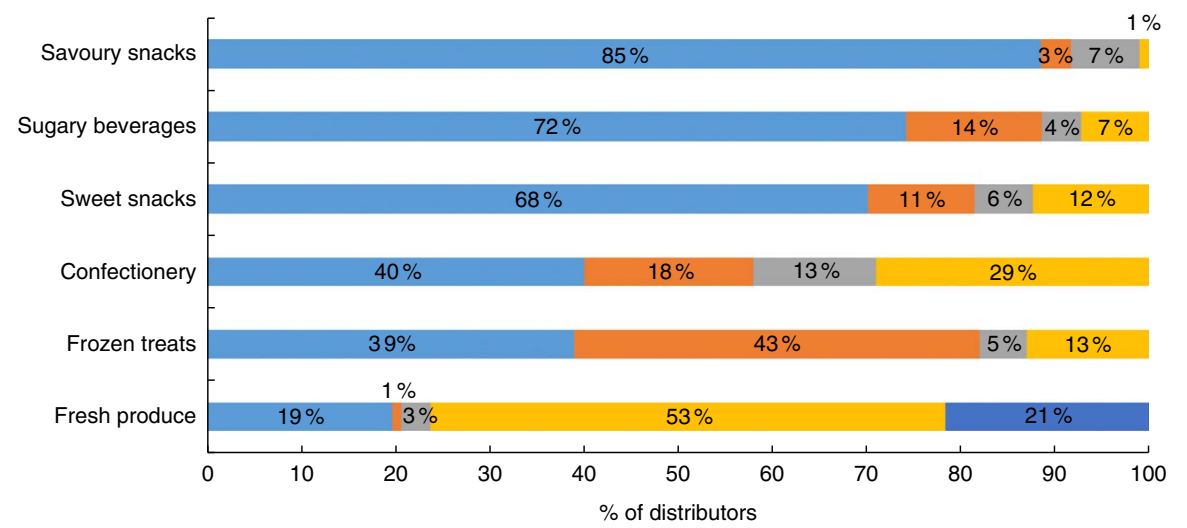

Fig. 1 Distributor visit frequency by product category: the percentage of distributors who sourced each of the product categories at varying levels of frequency ( $\square$, weekly; $\square$, monthly; $\square$, quarterly to annually; $\square$, self-source; $\square$, do not carry) as reported by small store owners/managers $(n$ 72) in four urban areas in the USA (Baltimore, MD; Durham, NC; Minneapolis/St Paul, MN; and San Diego, CA), mid-October 2013 to July 2014. Percentages do not sum to $100 \%$ due to missing data (savoury snacks: $n 3$ (4\%); sweet snacks, sugary beverages and fresh produce: $n 2(3 \%)$ each). Self-source refers to store owners/managers obtaining the product themselves

Table 3 The distributor in the placement and promotion of obesogenic products in small food storest in four urban areas in the USA (Baltimore, MD; Durham, NC; Minneapolis/St Paul, MN; and San Diego, CA), mid-October 2013 to July 2014

\begin{tabular}{|c|c|c|c|c|c|c|c|c|c|c|}
\hline & \multicolumn{2}{|c|}{$\begin{array}{l}\text { Savoury snack } \\
(n 71)\end{array}$} & \multicolumn{2}{|c|}{$\begin{array}{c}\text { Sugary beverage } \\
(n \text { 67) }\end{array}$} & \multicolumn{2}{|c|}{$\begin{array}{l}\text { Sweet snack } \\
(n 63)\end{array}$} & \multicolumn{2}{|c|}{$\begin{array}{c}\text { Confectionery } \\
(\text { ( } 51)\end{array}$} & \multicolumn{2}{|c|}{$\begin{array}{l}\text { Frozen trea } \\
\quad(n 64)\end{array}$} \\
\hline & $\%$ & $n$ & $\%$ & $n$ & $\%$ & $n$ & $\%$ & $n$ & $\%$ & $n$ \\
\hline \multicolumn{11}{|l|}{ Type of agreements with distributor } \\
\hline No agreement & 16 & 11 & 12 & 8 & 31 & 19 & 29 & 14 & 16 & 10 \\
\hline Informal & 41 & 28 & 37 & 25 & 62 & 38 & 57 & 28 & 44 & 28 \\
\hline Formal or both types & 43 & 30 & 51 & 34 & 7 & 4 & 14 & 7 & 40 & 25 \\
\hline Missing & & 2 & & 0 & & 2 & & 2 & & 1 \\
\hline Incentives provided & \multicolumn{2}{|c|}{$(n 58)$} & \multicolumn{2}{|c|}{$(n 59)$} & \multicolumn{2}{|c|}{$(n$ 42) } & \multicolumn{2}{|c|}{$(n$ 35) } & \multicolumn{2}{|c|}{$(n 53)$} \\
\hline Displays & 98 & 57 & 86 & 51 & 98 & 40 & 83 & 31 & 93 & 49 \\
\hline Free/discounted products & 40 & 23 & 63 & 37 & 20 & 8 & 80 & 28 & 25 & 13 \\
\hline Signage/marketing & 24 & 14 & 53 & 31 & 17 & 7 & 46 & 16 & 21 & 11 \\
\hline Slotting payments & 26 & 15 & 12 & 7 & 7 & 3 & 20 & 7 & 15 & 8 \\
\hline \multicolumn{11}{|l|}{ Distributor expectations for incentives } \\
\hline Price control & 57 & 33 & 44 & 26 & 45 & 19 & 20 & 7 & 19 & 10 \\
\hline Location control & 52 & 30 & 49 & 29 & 31 & 13 & 37 & 13 & 26 & 14 \\
\hline Employee promotion & 9 & 5 & 5 & 3 & 0 & 0 & 6 & 2 & 0 & 0 \\
\hline Other§ & 16 & 9 & 15 & 9 & 2 & 1 & 23 & 8 & 19 & 10 \\
\hline Locations under distributor control $\|$ & \multicolumn{2}{|c|}{$(n$ 42) } & \multicolumn{2}{|c|}{$(n 36)$} & \multicolumn{2}{|c|}{$(n 24)$} & \multicolumn{2}{|c|}{$(n 18)$} & \multicolumn{2}{|c|}{$(n 37)$} \\
\hline End caps & 74 & 31 & 14 & 5 & 58 & 14 & 33 & 6 & 8 & 3 \\
\hline Shelf aisle & 64 & 27 & 19 & 7 & 46 & 11 & 50 & 9 & 11 & 4 \\
\hline Checkout & 17 & 7 & 8 & 3 & 8 & 2 & 50 & 9 & 19 & 7 \\
\hline Free-standing displays/coolers & 43 & 18 & 94 & 34 & 26 & 6 & 39 & 7 & 81 & 30 \\
\hline
\end{tabular}

$\dagger$ Analyses exclude stores that self-sourced products (one savoury snack; five sugary beverage; nine sweet snack; twenty-one confectionery; eight frozen treat). fDenominator $=$ stores with either informal or formal agreements.

§Other includes maintenance of agreement; exclusivity of product in display; percentage of shelf space devoted to product.

$\|$ Denominator = number of stores with distributors' agreements and a little-to-total control over displays per store owner/manager report.

were slotting payments for sourcing a product or placing products in a certain location in the store, although these were reported among $26 \%$ of savoury snack and $20 \%$ of confectionery distributors. When examining differences by store size, smaller $v$. larger stores were less likely to receive free/discounted products from sugary beverage $(50 \% v .86 \%, P \leq 0.01)$ and frozen treat $(8 \% v$. $39 \%, \quad P \leq 0.01)$ distributors, free signage/marketing materials from savoury snack $(10 \% v .50 \%, P \leq 0.001)$, sugary beverage $(37 \% v .73 \%, P \leq 0.01)$ and frozen treat
(8\% v. 35\%, $P \leq 0.05)$ distributors, and slotting payments $(17 \%$ v. $41 \%, P \leq 0.05)$ from savoury snack distributors (see Table 4). When examining differences by store ethnicity, ethnic $v$. non-ethnic stores were less likely to receive free/discounted products $(58 \% v .91 \%, P \leq 0 \cdot 05)$ from confectionery distributors, as well as slotting payments from sugary beverage $(0 \% v .21 \%, P \leq 0 \cdot 01)$, confectionery $(0 \% v .30 \%, P \leq 0.05)$ and frozen treat (0\% v. 27\%, $P \leq 0.01)$ distributors. No other differences were significant. 
Table 4 Differences by store size and ethnicity in distributors' role in the placement and promotion of obesogenic products in small food storest in four urban areas in the USA (Baltimore, MD; Durham, NC; Minneapolis/St Paul, MN; and San Diego, CA), mid-October 2013 to July 2014

\begin{tabular}{|c|c|c|c|c|c|}
\hline & $\begin{array}{l}\text { Savoury } \\
\text { snack (\%) }\end{array}$ & $\begin{array}{c}\text { Sugary } \\
\text { beverage (\%) }\end{array}$ & $\begin{array}{c}\text { Sweet } \\
\text { snack (\%) }\end{array}$ & $\begin{array}{c}\text { Confectionery } \\
(\%)\end{array}$ & $\begin{array}{c}\text { Frozen } \\
\text { treat }(\%)\end{array}$ \\
\hline Incentives provided: Free/discounted products & $(n 23)$ & $(n 37)$ & $!(n 8)$ & $(n 28)$ & $(n 13)$ \\
\hline Smaller & & 50 & & & 8 \\
\hline Larger & & $86^{\star *}$ & & & $39^{\star *}$ \\
\hline Ethnic & & & & 58 & \\
\hline Non-ethnic & & & & $91^{*}$ & \\
\hline Incentives provided: Signage/marketing & $(n 14)$ & $(n 31)$ & $(n 7)$ & $(n 16)$ & $(n 11)$ \\
\hline Smaller & 10 & 37 & & & 8 \\
\hline Larger & $50^{\star \star *}$ & $73^{\star *}$ & & & $35^{\star}$ \\
\hline Incentives provided: Slotting payments & $(n 15)$ & $(n 7)$ & $(n 3)$ & $(n 7)$ & $(n 8)$ \\
\hline Smaller & 17 & & & & \\
\hline Larger & $41^{*}$ & & & & \\
\hline Ethnic & & 0 & & 0 & 0 \\
\hline Non-ethnic & & $21^{\star \star}$ & & $30^{*}$ & $27^{\star \star}$ \\
\hline $\begin{array}{l}\text { Distributor expectations for incentives: Price } \\
\text { control }\end{array}$ & $(n 33)$ & $(n 26)$ & $(n 19)$ & $(n 7)$ & $(n 10)$ \\
\hline Ethnic stores & & & 69 & & \\
\hline Non-ethnic stores & & & $31^{*}$ & & \\
\hline
\end{tabular}

${ }^{\star} P \leq 0.05,{ }^{* \star} P \leq 0.01,{ }^{\star \star \star} P \leq 0.001$.

†Analyses exclude stores that self-sourced products (one savoury snack; five sugary beverage; nine sweet snack; twenty-one confectionery; eight frozen treat).

Price and location control were the most common expectations that distributors had for placing and promoting their products (see Table 3), these being most common among savoury snack and sugary beverage distributors. Far less frequently, owners/managers reported that distributors expected employees to promote their products (ranging from $0 \%$ for sweet snacks and frozen treats to $9 \%$ for savoury snacks). There were no significant differences in distributor expectations by store size. In terms of store ethnicity, only one association was significant. In ethnic $v$. non-ethnic stores, sweet snack distributors were more likely to control the price of items (69\% v. 31\%, $P \leq 0 \cdot 05$; see Table 4).

Finally, among stores in which distributors had some control over the placement and promotion of their products, the most common locations where products were placed included end caps and other free-standing displays (see Table 3). However, location of control varied by product category, with savoury snack and sweet snack distributors favouring end caps $(74 \%$ and $58 \%$, respectively) and shelf aisles (64\% and $46 \%$, respectively), while sugary beverage ( $94 \%)$ and frozen treat (81\%) distributors favoured free-standing displays. Confectionery distributors were noted to have location control in all four location types (end caps, store aisles, checkout and free-standing displays/coolers). Differences by store size and store ethnicity were not examined given small cell sizes.

\section{Discussion}

The retail food environment in racially/ethnically diverse and lower-income communities is often characterized as unhealthy and full of energy-dense, nutrient-poor foods and beverages conveniently available through various retail food outlets ${ }^{(41)}$. Food stores are a significant source of nutrients ${ }^{(11)}$, and small food stores play a unique and important role in the retail food environment. Small food stores are important to study given that they are typically situated in convenient locations, especially to those with limited transportation options ${ }^{(10)}$; they are visited frequently to purchase a lot of energy quickly (e.g. spend \$US 3.00 on $2720 \mathrm{~kJ}$ ( $650 \mathrm{kcal})$ of immediately consumable products $^{(42)}$, during a shopping trip that averages less than $10 \mathrm{~min}^{(43)}$ ); and the ubiquity of obesogenic products in these stores has implications on what is purchased ${ }^{(34)}$. Access to a small food store is associated with risk for obesity ${ }^{(44)}$. The present study sought to fill a gap in this research by examining the importance of food and beverage distributors in the sourcing, placement and promotion of several obesogenic product categories. It is among the first studies to ask small food store owners/managers about the agreements they have with food and beverage distributors of these product categories and the incentives they receive for placing and promoting their products in these stores.

Study findings indicated that most distributors of the obesogenic product categories visited the stores at least weekly. By comparison, close to a quarter of the stores did not stock any fruits and vegetables and slightly over half sourced it themselves. This has important implications on the sustainability of healthy food access initiatives, particularly given the amount of support provided by the obesogenic product category distributors. Seventy per cent or more of the stores had informal or formal agreements with the obesogenic product category distributors. Incentives accompanied these agreements, as well as 
expectations for placing and promoting the products in the stores. Given the provision of free-standing displays and signage/marketing materials as incentives, product placement and promotion were a natural part of this agreement. These findings differ from those of a 1999 study by Feighery et $a l .{ }^{(29)}$, with more stores in the present study reporting having received incentives for placing products compared with Feighery et al. (e.g. $86 \%$ in the present study $v .52 \%$ of stores reporting receiving incentives from sugary beverage distributors). This may be because these industries have become more sophisticated over time in the placement and promotion of their products. Finally, we explored whether distributor relationships differed by store size or store ethnicity and found few differences. Small stores were more likely to self-source products and this was observed for both sugary beverages and fruits and vegetables. Smaller stores and ethnic stores were also less likely to receive various types of incentives compared with larger stores and non-ethnic stores, respectively. The most notable of these differences was the lack of slotting payments for ethnic $v$. non-ethnic stores from among several distributors. These are new findings as yet unreported in the retail food environment literature; however, they are based on a relatively small sample size. Additional research is needed to confirm these findings.

\section{Study limitations}

First, to minimize respondent burden, owners/managers were asked to think about their most common experience with distributors from each product category (e.g. 'I understand that you have many different relationships/ agreements with these distributors. When answering these questions, tell me about the most common ones, the average person or company.'). It is possible that owners/ managers have different relationships with different distributors of the same product category. Second, and also due to concerns with respondent burden, our healthy comparison of fresh fruits and vegetables was limited to questions on frequency of sourcing. Third, and for similar reasons, we did not conduct a formal assessment of testretest reliability (e.g. interviewing the owner/manager again two weeks after the first assessment). Fourth, although the multi-site nature of the study is a strength, site differences were observed, similar to a previous study ${ }^{(3)}$. For example, the Minneapolis/St. Paul site has a city ordinance requiring availability of fresh fruits and vegetables in its stores, thus the reason why all stores had fruits and vegetables. On the other hand, Baltimore stores generally self-sourced fruits and vegetables. Site differences made comparisons more challenging but we attempted to address this by examining distributors' roles by store size and store ethnicity, which varied across sites. Fifth, our operationalization of store size using annual sales and store ethnicity using observed measures of the in-store environment require further exploration given differences observed despite the small cell sizes.
Examining differences between small stores, larger grocery stores and supermarkets is an important next step, as is examining the extent to which these findings generalize across different types of ethnic stores. Finally, future research should explore how profitability of these products influences these relationships, particularly given price controls reported by store owners/managers.

\section{Conclusion}

The present study identified new and important findings on the importance of distributors of energy-dense, nutrient-poor foods and beverages in the sourcing, placement and promotion of products in small food stores. Specifically, we found that distributors of savoury products, sugary beverages, sweet snacks, confectionery and frozen treats are quite involved in ensuring product availability, a phenomenon that was not observed in a previous study among fruit and vegetable distributors ${ }^{(28)}$. Based on these findings, public health advocates and practitioners working to increase healthy food access need to understand the existing relationships between store owners/managers and distributors of both healthy and unhealthy foods and beverages, and what barriers the owners/managers may face in terms of sourcing, placing and promoting certain products in their stores. Interventions that address healthy food availability without taking into account the larger food system may face setbacks in terms of impacting customer dietary intake or purchasing of the healthier food and/or beverage products. More research is needed to understand how to work with retailers that have existing agreements for obesogenic products at the point of sale. Similarly, more research is needed to find ways to work with distributors to restructure agreements to incentivize the promotion of healthier foods and beverages. Thus, in order to address access to healthy foods and beverages, as well as limit access to unhealthy products, healthy store partnerships must consider the role of the distributors.

\section{Acknowledgements}

Acknowledgements: The authors thank the store managers who agreed to participate in this study. In addition, the authors thank Maria Tólman for her excellent translation of the interview guide and recruitment scripts and materials, and Susan P Liverman, RN, Johns Hopkins University, for her leadership on qualitative data management and analysis. Financial support: This research was supported by the Healthy Eating Research programme of the Robert Wood Johnson Foundation (grant number 0000704651). However, Healthy Eating Research had no role in the design, analysis or writing of this article. Conflict of interest: None of the authors have a conflict of interest 
with this work. Authorship: G.X.A., J.G., M.L. and K.R. conceptualized the study and prepared the proposal for funding. All authors participated in creating the data collection materials and protocols. A.K., C.O. and L.S.S. were involved in data collection and L.H. was primarily responsible for data management. G.X.A. conducted the analyses and L.H. carried out data and analysis verification. G.X.A. prepared a first draft of the paper and all authors read and approved several versions, including the final manuscript. Ethics of human subject participation: This study was conducted according to the guidelines laid down in the Declaration of Helsinki and all procedures involving human participants were approved by the Institutional Review Board at each of the authors' institutions. Verbal informed consent was witnessed and formally recorded.

\section{References}

1. Whitehouse A, Simon A, French SA et al. (2012) Availability of snacks, candy and beverages in hospital, community clinic and commercial pharmacies. Public Health Nutr 15 , $1117-1123$

2. Farley TA, Rice J, Bodor JN et al. (2009) Measuring the food environment: shelf space of fruits, vegetables, and snack foods in stores. J Urban Health 86, 672-682.

3. Laska MN, Borradaile KE, Tester J et al. (2010) Healthy food availability in small urban food stores: a comparison of four US cities. Public Health Nutr 13, 1031-1035.

4. Astrup A, Bovy MW, Nackenhorst K et al. (2006) Food for thought or thought for food? - a stakeholder dialogue around the role of the snacking industry in addressing the obesity epidemic. Obes Rev 7, 303-312.

5. Drewnowski A \& Rehm CD (2013) Energy intakes of US children and adults by food purchase location and by specific food source. Nutr J 12, 59.

6. Ambrosini GL (2014) Childhood dietary patterns and later obesity: a review of the evidence. Proc Nutr Soc 73, 137-146.

7. Newby PK (2007) Are dietary intakes and eating behaviors related to childhood obesity? A comprehensive review of the evidence. J Law Med Ethics 35, 35-60.

8. Moreno LA \& Rodríguez G (2007) Dietary risk factors for development of childhood obesity. Curr Opin Clin Nutr Metab Care 10, 336-341.

9. Food Marketing Institute (2016) US Grocery Shopper Trends 2016. http://www.fmi.org/docs/default-source/webinars/fmi2016-us-grocery-shopper-trends-overview-webinar5ce703032 4aa67249237ff0000c12749.pdf?sfvrsn=2 (accessed January 2017).

10. Powell LM, Slater S, Mirtcheva D et al. (2007) Food store availability and neighborhood characteristics in the United States. Prev Med 44, 189-195.

11. Poti JM \& Popkin BM (2011) Trends in energy intake among US children by eating location and food source, 1977-2006. J Am Diet Assoc 111, 1156-1164.

12. Lawman HG, Vander Veur S, Mallya G et al. (2015) Changes in quantity, spending, and nutritional characteristics of adult, adolescent and child urban corner store purchases after an environmental intervention. Prev Med 74, 81-85.

13. Lent MR, Vander Veur SS, McCoy TA et al. (2014) A randomized controlled study of a healthy corner store initiative on the purchases of urban, low-income youth. Obesity (Silver Spring) 22, 2494-2500.

14. Gittelsohn J, Rowan M \& Gadhoke P (2012) Interventions in small food stores to change the food environment, improve diet, and reduce risk of chronic disease. Prev Chronic Dis 9. E59.

15. Paek H-J, Oh HJ, Jung $\mathrm{Y}$ et al. (2014) Assessment of a healthy corner store program (FIT Store) in low-income, urban, and ethnically diverse neighborhoods in Michigan. Fam Community Health 37, 86-99.

16. Ayala GX, Baquero B, Laraia BA et al. (2013) Efficacy of a store-based environmental change intervention compared with a delayed treatment control condition on store customers' intake of fruits and vegetables. Public Health Nutr 16, 1953-1960.

17. Song H-J, Gittelsohn J, Kim M et al. (2009) A corner store intervention in a low-income urban community is associated with increased availability and sales of some healthy foods. Public Health Nutr 12, 2060-2067.

18. Bleich SN, Herring BJ, Flagg DD et al. (2012) Reduction in purchases of sugar-sweetened beverages among lowincome Black adolescents after exposure to caloric information. Am J Public Health 102, 329-335.

19. Papies EK, Potjes I, Keesman M et al. (2014) Using health primes to reduce unhealthy snack purchases among overweight consumers in a grocery store. Int J Obes (Lond) $\mathbf{3 8}$, 597-602.

20. Monteiro CA, Moubarac JC, Cannon G et al. (2013) Ultra-processed products are becoming dominant in the global food system. Obes Rev 14, Suppl. 2, 21-28.

21. John R, Cheney MK \& Azad MR (2009) Point-of-sale marketing of tobacco products: taking advantage of the socially disadvantaged? J Health Care Poor Underserved 20, 489-506.

22. Feighery EC, Ribisl KM, Clark PI et al. (2003) How tobacco companies ensure prime placement of their advertising and products in stores: interviews with retailers about tobacco company incentive programmes. Tob Control 12, 184-188.

23. Laws MB, Whitman J, Bowser DM et al. (2002) Tobacco availability and point of sale marketing in demographically contrasting districts of Massachusetts. Tob Control 11, Suppl. 2, ii71-ii73.

24. Caspi CE, Pelletier JE, Harnack L et al. (2016) Differences in healthy food supply and stocking practices between small grocery stores, gas-marts, pharmacies and dollar stores. Public Health Nutr 19, 540-547.

25. Cohen DA \& Babey SH (2012) Contextual influences on eating behaviours: heuristic processing and dietary choices. Obes Rev 13, 766-779.

26. Achrol RS (2011) Slotting allowances: a time series analysis of aggregate effects over three decades. J Acad Mark Sci $\mathbf{4 0}$, 673-694.

27. Wilkie WL, Desrochers DM \& Gundlach GT (2002) Marketing research and public policy: the case of slotting fees. J Public Policy Mark 21, 275-288.

28. Jetter KM \& Cassady DL (2010) Increasing fresh fruit and vegetable availability in a low-income neighborhood convenience store: a pilot study. Health Promot Pract 11, 694-702.

29. Feighery EC, Ribisl KM, Achabal DD et al. (1999) Retail trade incentives: how tobacco industry practices compare with those of other industries. Am J Public Health 89, 1564-1566.

30. Budd N, Cuccia A, Jeffries JK et al. (2015) B'More Healthy: Retail Rewards - design of a multi-level communications and pricing intervention to improve the food environment in Baltimore City. BMC Public Health 15, 283.

31. Hattersley L (2013) Agri-food system transformations and diet-related chronic disease in Australia: a nutrition-oriented value chain approach. Agric Hum Values 30, 299-309.

32. Novotny R, Vijayadeva V, Ramirez V et al. (2011) Development and implementation of a food system intervention to prevent childhood obesity in rural Hawai'i. Hawaii Med J 70, 7 Suppl. 1, 42-46. 
33. Cannuscio CC, Tappe K, Hillier A et al. (2013) Urban food environments and residents' shopping behaviors. Am J Prev Med 45, 606-614.

34. Sharkey JR, Dean WR, Nalty CC et al. (2013) Convenience stores are the key food environment influence on nutrients available from household food supplies in Texas Border Colonias. BMC Public Health 13, 45.

35. Ogden CL, Carroll MD, Lawman HG et al. (2016) Trends in obesity prevalence among children and adolescents in the United States, 1988-1994 through 2013-2014. JAMA 315, 2292-2299.

36. Glanz K \& Yaroch AL (2004) Strategies for increasing fruit and vegetable intake in grocery stores and communities: policy, pricing, and environmental change. Prev Med 39, Suppl. 2, S75-S80.

37. Lee JGL, Henriksen L, Myers AE et al. (2014) A systematic review of store audit methods for assessing tobacco marketing and products at the point of sale. Tob Control $\mathbf{2 3}$, 98-106.

38. Gittelsohn J, Laska MN, Andreyeva T et al. (2012) Small retailer perspectives of the 2009 Women, Infants and Children Program food package changes. Am J Health Behav 36, 655-665.
39. Gittelsohn J, Laska MN, Karpyn A et al. (2014) Lessons learned from small store programs to increase healthy food access. Am J Health Behav 38, 307-315.

40. Ayala GX, Laska MN, Zenk SN et al. (2012) Stocking characteristics and perceived increases in sales among small food store managers/owners associated with the introduction of new food products approved by the Special Supplemental Nutrition Program for Women, Infants, and Children. Public Health Nutr 15, 1771-1779.

41. Odoms-Young AM, Zenk SN, Karpyn A et al. (2012) Obesity and the food environment among minority groups. Curr Obes Rep 1, 141-151.

42. Lent MR, Vander Veur S, Mallya G et al. (2015) Corner store purchases made by adults, adolescents and children: items, nutritional characteristics and amount spent. Public Health Nutr 18, 1706-1712.

43. Calderon J, Ayala GX, Elder JP et al. (2017) What happens when parents and children go grocery shopping? An observational study of Latino dyads in Southern California, USA. Health Educ Behav 44, 5-12.

44. Bodor JN, Rice JC, Farley TA et al. (2010) The association between obesity and urban food environments. J Urban Health 87, 771-781. 